\title{
Study on Systems Modeling of Students Support Service in Distance and Open Education
}

\author{
Li Qiang , Wang Xiaoming \\ No.1 Yingshui Road, Nankai District ,Tianjin 300191, China \\ Tianjin Open University \\ hmw189@126.com
}

Keywords: Systems Modeling; Students Support Service; Distance and Open Education

\begin{abstract}
Students support service as the characteristics and advantages plays a large role increasingly in distance and open education, while the educators from the distance and open education are practicing their work deeply. As a new mode of education, the Open University has to further make the connotation and function of students support service clear and fixed. In order to benefit the construction of students support service system at the Open University, an analysis is made on its structure of students support service from the perspective of system science to reveal the target, reveal formation of driving force for the dropout rate, the structure and model characteristics of the system at such a university in this paper.
\end{abstract}

\section{Introduction}

The Open University of China has its mission target to focus on the formation of large-scale professional and remote information team to serve students, strengthen the interaction between teachers and learners, and track the learning record of the students as well as provide the learners with a thoughtful and personalized remote learning support services. As a result, a new mode, combining the internal remote learning support service with the external public service, will be set up $^{[1]}$.

In order to meet the new mission objectives and higher education requirements, it is necessary for the connotation and functional structure of students support service system to be fixed, for the students support service structure at the Open University to be studied and for students support service system model to be built up. It is hoped that the study in this paper, made on the basic functions and characteristics of students support service system here, offers a few commonplace remarks so that many other valuable opinions can be presented.

\section{Overview on Students Support Services System}

The essence of the study on the students support services system lies in whether the concerned problems can be systematically analyzed, whether the integrity and every aspects of students support services system can be grasped and whether a scientific decision can be made. In order to realize and study the system structure of the new mode of the Open University, one should first understand the concept of the system and the basic principle of its systematic science ${ }^{[2]}$.

The systematic science requires us to study the objective world in view of integrity, structure and function of the system, to explore the relation among the elements, structure, information of the system and their control with each other and to find out the property and regularity in the knowledge system. The study on the problems in systematic science must be done with systematical significance $^{[3] \text {. }}$

The ideas and concepts of students support service come from the rich remote education practice at the British Open University. Professor David Sewart defined students support as a means and by this means, the learners could complete their study by taking the full advantage of the various functions, presented by distance education institutions ${ }^{[4]}$.

The students support service system is a self-organizing system with the characteristics of the 
educated personnel as the dominant. Such a system has not only an organizational environment (system) with educators to provide a support service to the students as the main, but also a service capability, composed of external environment, which is adapted to the need for education. Therefore, it is necessary for the students-support-service-constituted elements and the logic relation between the elements to be analyzed so as to explore the integral promoting effect on the quality of students support service and provide a scientific analysis perspective for controlling and guiding the students support service system.

When the students support service system is studied, some issues cannot be ignored, including the environmental factors of the students support service system as well as the systematic concept of the existence and development. The environment of students support service system consists of education policy, social environment, regionally economic development status, population and natural environment as well as modern information technology transformation, etc. The mutual effect and interaction between students support service system and its environment can ensure the goal of fostering the ability of talents to be achieved. Based on intrinsic development logic of higher education, the concept of students support service system follows up the orders of nature, the rules of economy and the laws of social development to fully demonstrate the characteristics of the integrity, correlation, hierarchy, ordering, purpose, and dynamic of the students support service system. The mathematical model concerned is shown as the follows:

$$
S y=\{i, c, h, o, p, d\}
$$

\section{Analysis on Students Support Service System}

A. Elements of students support service system

According to Ludwig Von Bertalanffy's General Systems Theory ${ }^{[5]}$, the students support service system (see figure 1) is composed of the four elements of the educators, educated personnel, teaching resources and educational technology ${ }^{[6]}$.

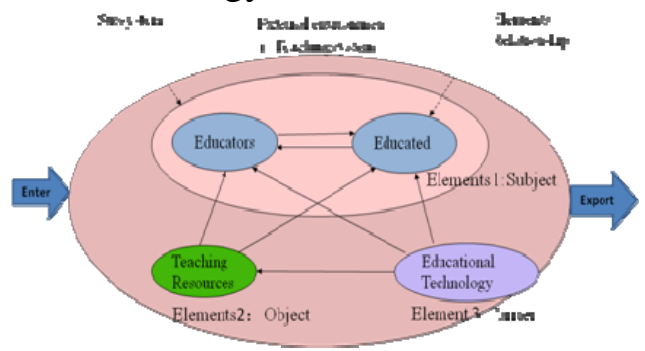

Figure 1. Students support service system

Educators play a dominant role between the elements of the students support service system and educated personnel act as the main body in the system. The both educators and educated personnel together form a closed loop according to the information, fed back with each other. The teaching resources are the essential object in the support service and the educational technology serves as the carrier in the whole course of students support service, both of which constitute a learning environment of students support service system. By multilateral effects among the four elements between the educators and educated personnel, the students support service system has certain synergies, self-organization and the integral emergence.

$B$. Theoretical basis of the students support service system

1) Operational research theory

The operations research theory of students support service system, with maximizing the quality and capability of supporting service to the students as the goal and from the system point of view, requires the limited resources to be rationally allocated, comprehensively arranged and integrally planed, including some issues of students support service agency setting, teaching team building-up, relative platform establishment and input-output in addition to making the service objective and means clear. At the same time, it is necessary not only for the constraints of school conditions, but also for the personalized learning needs of the educated personnel at the new type of open education to be taken into account in addition that the impact from the educational policies, socio-economic, 
demographic and environmental factors is to be considered.

2) Cybernetics (Intervention theory)

The students support service behavior itself is a process of intervention and it can maintain the quality of training the ability of talents at an ideal state through a continuing intervention process. The control refers to the behavior of the target, selected according to the relative information and process to realize this process (see figure 2). The behavior of the system can be effectively controlled to ensure the service quality by analyzing the structure of students support service system with "the learners as the center" and setting up the intervention points at the six key links of "teaching work supporting service," "management supporting service," "practice supporting service," "resources supporting service," "learning-assisted supporting service” and "technique supporting service" ${ }^{[7]}$.

This system runs on purpose and it can be automatically corrected by itself in accordance with the learning target of educated personnel and the change of environmental factors. The most ultimate purpose of the behavior of the system is to provide a two-way interaction through the network by use of modern information technique and to allow educated personnel to realize their scheduled target through gaining professional knowledge and overcoming every factor that may have an impact on their learning by use of different forms of service.

\section{3) Information theory}

The students support service system uses the method of information theory to integrally study the teaching work, students, management, technique, platform, learning process and all useful information related to students learning to provide a basis for the education administrative sectors to make a significant decision. The method of mathematical statistics will be used to value the work state of students support service system and especially to aggregate education information as well as analyze the relation between the need and demand of the market, the forefront of disciplines, the content of teaching work, the learning suggestions, the learning resources, the learning status of the students, the application of new techniques, the pass of relative studies and the transformation rule.

4) Science of complexity

Science of complexity is a new theory, developed from systematic science and it is an emerging scientific research morphology with "multiple disciplines interacted" by taking complex systems as the research object, surpassed reduction theory as the characteristics of the methodology, revealment and explanation of operation rule of the complex system operation as the major task, and improvement of people's ability to understand, explore and transform world as the main objective $^{[8]}$.

\section{Construction of Students Support Service System at the Open University}

\section{A. Basic connotation of the Open University}

There are five basic ideas that may embody the value orientation of the Open University, including openness, responsibility, quality, diversification and internationalization. That is to emphasize the open mind, the open mode, the open teaching method and the open learning object, and it means to provide a learning opportunity and service to those, who have ability and are willing to receive higher education, by making a full use of advanced science and technology to carry out remote education ${ }^{[9]}$.

\section{B. $\quad$ Construction of students support service system}

In accordance with the principles of the systematic science, the structure of the students support service system at the Open University refers to the various internal and practical forms, which make up the students support service system, and the steadily mutual linkage among each sub-system as well as the combination of the functions and elements of these sub-systems. The students support service system at the Open University with "learners as the center" is composed of multiple hierarchy with the features of specific functions and elements of the sub-systems. These elements are interrelated, mutual restrained and interacted with each other to realize the overall operation goal of the system (see figure2). 


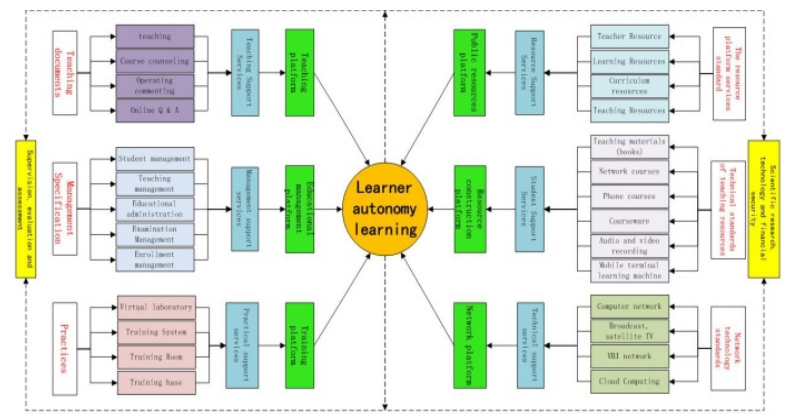

Figure 2. Structure of students support service system at the Open University

The students support service system at the Open University is a social structure system, consisting of a number of elements and functions. As the a part of lifelong education support service of the state, the system is closely interacted with the social, political, economic, technological and cultural and environmental elements of the country.

C. $\quad$ Neural network model of students support service system

Hopfield network is a non-linear mapping relationship for Sigmoid function neural elements interconnected network composed, it belongs to a continuous nonlinear dynamic model, Its state space expression as follows:

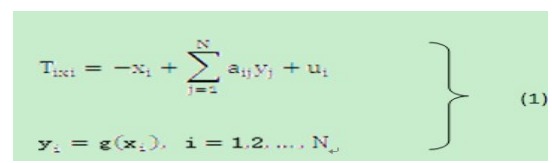

Student support services network is formed by many single layer networks, which interacts each other internally and connects each other logically rationally, making it an independent non-linear dynamic systems model. The variety of support services network forms a complicated service system, especially for continuous nonlinear dynamic system identification model.

The students support service system is a relatively independent neural network system as shown in figure 3.

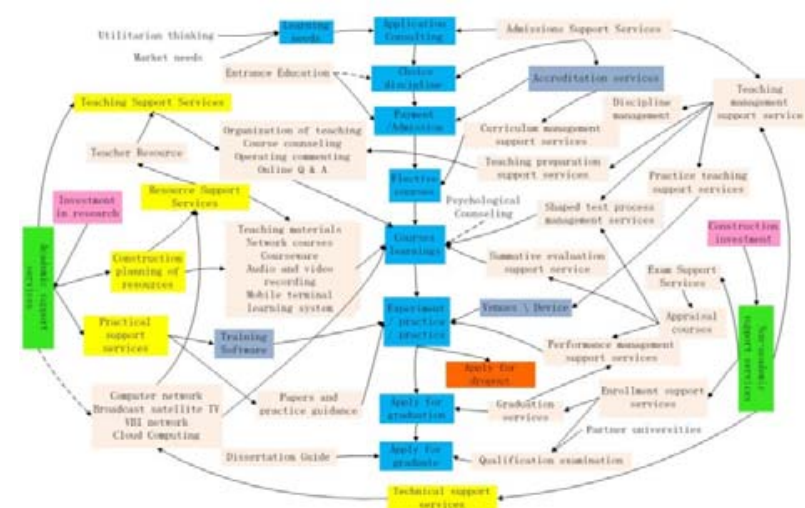

Figure 3. Neural network model of students support service system

This system is a basic component---neurons, composed of many support service sub-systems. They are interacted with each other and the logically reasonable linked up to become relatively independent and self-adapted nonlinear dynamic systems. Such a service system, generated by the combination of so many support service neurons together, has very complex behavior and it can reflect the dynamic non-linear characteristics of the students support service system ${ }^{[10]}$.

Continuous time neural network model of student support services primarily to achieve the following tasks:

- Its convergence will eventually make the student support services neural network converges to a state of equilibrium - that is: a balance between supply and demand.

- It has a finite number of equilibrium point.

- If the equilibrium is stable, then it must be gradual and stable.

- Asymptotically stable equilibrium point is the minimum of the energy function of student support services system.

- The neural network learning any one orthogonal vectors can be stored as asymptotically 
stable equilibrium point.

- It explores the formation of driving force for dropout rate.

D. Features of students support service system at the Open University

When the features of students support service system at the Open University are studied with systematic science and complexity science, some other characteristics are also found, including the relevance of service content, the complexity of service process, the uncertainty of learning objective, self-organization of learning behavior and the emergence of integrity of study support service in addition to the characteristics of conventional systems.

\section{1) Relevance of service content}

The services, provided by the Open University to the students, can be divided into two types of academic support service and non-academic support service. The academic support service consists of personnel training positioning of formal schooling education and informal schooling education, market demand, curricula study, group discussion, practice internship and thesis, of which work, involving learning interaction and, policy guidance, will be mainly done by decision-making institution and (presiding) teachers who are in charge of curriculum construction. Non-academic support service is composed of the management policies, rules and norms, operational processes, psychological counseling, of which work will be carried on by the teachers concerned and administrative personnel. The teachers, administrative personnel and teaching support staff at different levels, at the same time, provide the relative support services to the educated personnel with an aim at helping them to solve the difficulties they meet during the study and complete their studies smoothly. Therefore, students support service has the content strongly related to the learning of the students.

2) Complexity of the service process

a) Adaptability between teaching and learning

There are two tasks given at the Open University. One is to do well the work of informal schooling education and the other formal schooling education as well to build up a bridge between the two types of education for them to make communication with each other. Two issues should be dealt well in face of the students. One is to meet the individual need of self-study and self-management from the students, create a good condition for the students with the teaching model to give attention to the learning requirements of individuals and help the learners to realize self-management. The other is to establish a collaborative learning mode and practical environment on the basis of "self-learning", in which the core is to enable students to complete the learning task "together" and have a touch on the reasonable collision between the relative theory and practice ${ }^{[11]}$.

b) Uncertainty of the learners

The Open University is the one fenceless. It will provide an opportunity to those who want to learn. In this way, the learners from any fields can come to it for a study. There are not only various characteristics of the natural material world in the learners' thinking, emotions, will, and behavior, but also other advanced and complex features, that there are not above. Regardless of race, gender, age, occupation, educational background, learners here can select different learning target, learning time and content as well as chose their own learning level and preference in accordance with their own expectation, which results in the uncertainty of the learners themselves to a large extent for they can at any time change their learning expectation and studying institutions according to their wishes and, at the mean time, a learner can also become an instructor of a learning task at a certain stage of study according to his expertise.

c) Uncertainty of learning objectives

The learning objectives of the learners in the future will be embodied with a strong stage. At different learning stages, the learning objectives will constantly change according to the difference of the environmental factors, the students may encounter, and the status, the students have mastered what they have learnt. Therefore, the learning objectives of the students will show an uncertainty to a large extent. All of this requires us to provide learning goals at different levels for learners to experience and meanwhile, we should ensure a reasonable linkage between the learning courses at different levels in the education. 


\section{d) Self-organization of learning behavior}

When the self-organization of students support service system occurs, there must be some conditions that output or input exists between the system and the environment, because there has to establish an orderly structure of dynamic in the system. For this reason, there must be an exchange of materials, energies and information between the system and the outside world and the input from outside, to which the system opens, reaches a certain threshold.

The phenomenon of self-organization of students support service system is an integral phenomenon effect, brought about under the non-linear action of multiple support service sub-systems. The non-linear action of the sub-system has a process as (i) evolution of support service from the disordered state to an ordered state, (ii) evolution of the organization capability of the support service from low level to high level, and (iii) evolution of support service at the same organization level from the simple process to the complex. The three processes above act with each other alternately to form a continuum of the organized students support service system.

e) Emergence of students support service system

The emergence is a complex phenomenon, caused by the simple interaction among the sub-structured units in a complex system and it is one of the important characteristics of the complex systems. The properties, features, behaviors and functions, which the system has integrally but a part of the system does not have, are called emergence by the complexity science. That means when the integrity of the system is reduced to each part of it, the properties, features behaviors and functions are impossible to be embodied in a single part of the system (see figure 4-A).

The essence of emergence is a surprising and complex system function, generated from small to large, from simple to complex and from small number of rules and laws. It is a macro-rule and a limited generation process by making replacement (see figures 4-B, C and D).

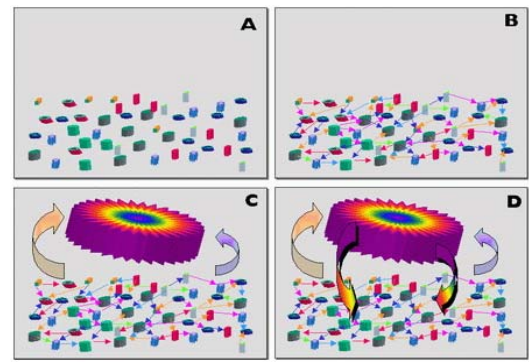

Figure 4. Emergence of the systematic developing procedure

The students support service system is an organic integrity for the educators and educated personnel to support with each other during the teaching and learning. Its emergence comes from the effects of three aspects together, including the constituted elements and structure of students support service as well as the external environment. The environmental effect, component effect, scale effect and, structural effect together create the emergence - the quality of students support service system to be promoted integrally (see figure 5).

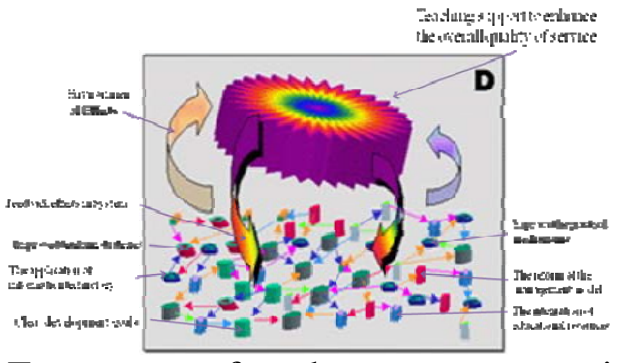

Figure 5. Emergence of students support service system

The characteristics of the emergence in the students support service system mainly include the limited generation, non-additive integrity and objective regularity.

The students support service system at the Open University itself is the best performance of the emergence of the system. It consists of some sub-systems of students enrollment support service, teaching support service, teaching management support service, practice-teaching support service, resources support service and technical support service. A single support service system is only a 
basic component of the students support service system. The improvement of the service function of only a sub-system cannot enhance the integral function of the students support service system and only the integral emergence is the essential features of the system. If the function of the students support service system is to be improved and its service ability is to be enhanced, it is necessary for the internal and external environments as well as the functional structures of each sub-system to be improved so as to stimulate a further evolution of the emergence in the students support service system.

\section{Conclusion}

In this paper, the structure of the students support system is analyzed by use of the systematic science and complexity theory and meanwhile, the students support service system at the Open University is described in combination of some basic theories, including operational science in detail, cybernetics and information theory with the structure and operation principle of the students support service system revealed in perspective of the systematic science, the characteristics of the students support service system preliminarily the structure and neural network model of the students support service creatively built up and the theoretical support to the construction of students support service system provided.

\section{Acknowledgment}

This research was financially supported by (i) The National Natural Science Foundation of China (Grant NO.70973148), (ii) The Humanities \& Social Science Fund of Tianjin Education Committee (NO.20082514), (iii) The Science Fund of the Open University of China ( NO. Q110052G).

\section{References}

[1,8] Yang Zhijian. Chinese National Open University’s Status and Role, "Study, technology and manpower development congress" on the opening ceremony of the speech in Beijing University, 2011.7.

[2] Miao Dongsheng. System Science Right, Chinese People's University Press, Beijing, 2010.3, pp.3-8.

[3,9] Xu Guozhi. Systems Science, Shanghai Science and Technology Education Press, Shanghai, 2000.9, pp12-16, pp.249-266.

[4] Wu Lizhi, Ding Xin. Student Support Service: David Sewart's Theory and Practice, Distance Education in China, 2008.1, pp.25.

[5] Ludwig Von Bertalanffy. General Systems Theory, New York: Braziller, 1968, pp 46-47.

[6] Michael C. Jackson. Systems thinking: Creative holism for managers, John Wiley \& Sons Ltd. 2003, pp 6-9.

[7] Yang Tingting, Wang Xiaoming. Distance and open education system: organization and management. China Central Radio and Television University Press, 2009.8.

[10] Xu Guozhi. Systems Science and Engineering: Theories and Applications, Shanghai Science and Technology Education Press, Shanghai, 2001.4, pp506-511.

[11] Ormond Simpson. Supporting Students in Online, Open and Distance Learning (Second Edition). Routledge, Taylor \& Francis Group, 2002.8. 